\title{
EL DEVENIR QUEER DE CLEOPATRA EN LA VIRGEN CABEZA DE GABRIELA CABEZÓN CÁMARA
}

\author{
Juan Martínez Gil \\ Universitat de Barcelona
}

\section{RESUMEN}

Con la publicación de La Virgen Cabeza en 2009, Gabriela Cabezón Cámara irrumpió en el panorama literario de la Nueva Narrativa Argentina con una propuesta innovadora que continuó desarrollando en sus novelas posteriores. Diversos investigadores han calificado su literatura como queer en base a las líneas teóricas desarrolladas por los estudios de género en relación con las identidades LGTBI. En el presente artículo nos proponemos analizar cómo se desarrolla esta apuesta queer en su primera novela a través de uno de sus personajes principales, Cleopatra. Partiendo de la estética neobarrosa de Néstor Perlongher, que se recrea en la acumulación kitsch de diferentes narrativas e imaginarios sociales, el personaje de Cleopatra explora diversas posiciones con respecto a su sexo y a su sexualidad sin seguir una secuencia o un orden fijo.

Palabras clave: estudios queer, Nueva Narrativa Argentina, neobarroso, Gabriela Cabezón Cámara, estudios trans.

THE BECOMING QUEER OF CLEOPATRA IN

GABRIELA CABEZÓN CÁMARA'S SLUM VIRGIN

\section{Abstract}

After publishing La Virgen Cabeza in 2009, Gabriela Cabezón Cámara bursted into the literary critical panorama of Argentinian New Narrative with an innovative proposal which the author kept on developing in the following novels. Different authors have described this proposal as «queer» based on theories developed by Gender Studies talking about LGTBI identities. This work offers an analysis of how this queer proposal works in her first novel through one of the main characters, Cleopatra. From Néstor Perlongher's neobarroso aesthetics, which recreates kitsch accumulation of different narratives and social imageries, the character of Cleopatra explores various sexual and gender positions, not following a sequence or fixed order, thus representing what different authors have named queer.

Keywords: Queer Studies, Argentinian New Narrative, Neobarroso, Gabriela Cabezón Cámara, Trans Studies. 


\section{UN APUNTE QUEER EN LA NUEVA NARRATIVA ARGENTINA}

Gabriela Cabezón Cámara (San Isidro, Buenos Aires, 1968) es una de las escritoras argentinas contemporáneas más valoradas por la crítica. Desde que en 2009 viera la luz La Virgen Cabeza, ha sido considerada de forma unánime como una de las mayores representantes de literatura queer (Ruiz), aunque también es ubicada en corrientes propias de la literatura argentina como «la novísima novela argentina» (Gallego), la «Nueva Narrativa Argentina» (Ponze), o más genéricamente en la «literatura social» (Tozzi).

Entre estas clasificaciones, es la que usa Alberto Ponze la que tiene más impacto en la historiografía literaria argentina contemporánea, así como la que más se ajusta, a mi parecer, a la producción de esta autora. "Nueva Narrativa Argentina» (NNA) es el término que acuñó Elsa Drucaroff para designar las novelas argentinas escritas desde los años 80 hasta la actualidad y que tienen como características básicas la impronta autobiográfica, los temas sociales y la figura del narrador como observador de aquella parte de la sociedad que permanece oculta, sin representación o con una representación demonizada. Alberto Ponze interpreta el papel del escritor como recuperador de la voz subalterna, pues trata siempre de reflejar estratos de la sociedad sin voz en los mass media o en el discurso hegemónico. En las obras de Gabriela Cabezón Cámara encontraremos esta intencionalidad a través de un ejercicio de empoderamiento narrativo que otorga voz a las travestis de las villas miseria (en La Virgen Cabeza, 2009), a las mujeres víctimas de trata (en Le viste la cara a Dios, 2012 / Beya, 2013), a lxs desahuciadxs (en Romance de la Negra Rubia, 2014), a las víctimas de la represión institucional en Argentina, Túnez o Siria (en $Y$ su despojo fue una muchedumbre, 2015) y a las "chinas» de la Pampa decimonónica (en Las aventuras de la China Iron, 2017)1.

Siguiendo la estela de Drucaroff y Ponze, resulta muy interesante la aproximación que realiza Guadalupe Maradei a las obras de Gabriela Cabezón Cámara como "ficciones postdictadura», en especial la denominada por la crítica como "Trilogía oscura», formada por La Virgen Cabeza, Beya (Le viste la cara a Dios) y el Romance de la Negra Rubia. Estas "ficciones postdictadura" hacen visible la extensión del control sobre cuerpos y poder de la última dictadura argentina (1976-1982) originada por el golpe de Estado del general Videla en 1976 y a la que siguió una polémica transición política. En el caso de Gabriela Cabezón Cámara, este control se representa a través de sus temáticas sociales y de la condición de supervivientes de sus protagonistas - las voces subalternas de las que hablábamos-. Para esta investigadora, las producciones de Gabriela Cabezón Cámara reflejan «de qué va sobrevivir en las democracias del capitalismo neolibreral $\aleph^{2}$.

1 Tanto Beya como $Y$ su despojo fue una muchedumbre son novelas gráficas en coautoría con el ilustrador Ińaki Echeverría. Beya es una adaptación de su novela corta Le viste la cara a Dios.

2 G. Maradei. «Ficciones postdictadura: la trilogía oscura de Gabriela Cabezón Cámara», en D. Ingenschay (ed.), Eventos del deseo: sexualidades minoritarias en las culturas-literaturas de 
No obstante, el presente artículo pretende profundizar en la concepción de la obra de nuestra autora como representante de una "propuesta de discurso queer» (Cabezón Cámara, Cabecita loca). En un primer acercamiento, el concepto de discurso o identidad queer no resulta en absoluto fácil de definir y ha sido problematizado por diferentes autores. David Córdoba, por ejemplo, define queer en términos de carácter radical, conflictivo, abierto y contingente, siendo necesaria su reivindicación como identidad, pero a la vez imposible, pues el sexo y la sexualidad tienen un carácter performativo y no esencial. A pesar de ello, precisamente este aspecto posibilita la subversión y reapropiación de enunciados diferentes que adoptan nuevos significados según el contexto.

También Paul B. Preciado establece una serie de políticas que caracterizan a los sujetos queer a partir de lecturas como Foucault, Deleuze y Guattari o Wittig. En «Multitudes queer» este autor ofrece una definición de queer que remarca su condición colectiva y propone cuatro políticas que practican estos cuerpos, que parten de lo que llama la «desterritorialización» de la heterosexualidad: la «desidentificación», las «identidades estratégicas», la «reconversión de las tecnologías del cuerpo» y la "desontologización de la práctica sexual». Como ocurre en el caso de Córdoba, Preciado también incide en la ambivalencia de la cuestión de la identidad, de forma que sus multitudes queer «responden con estrategias a la vez hiper-identitarias y post-identitarias y hacen un uso radical de los recursos políticos de producción performativa de las identidades desviadas» ${ }^{3}$.

Estas estrategias «postidentitarias» que explicita Preciado están muy relacionadas con el carácter interseccional que Javier Sáez, por su parte, insiste en reivindicar dentro del concepto de queer: «Los cuestionamientos [...] por grupos que incorporaban la cuestión racial, de clase, la discapacidad o relativas a lo decolonial (entre otras), como factores clave para entender el sexo, el género y la diversidad sexual» ${ }^{4}$. Por lo tanto, no solo podemos concebir un «discurso queer» de forma homogénea como una identidad o una no identidad LGTB, sino que también debemos incidir en cómo reivindica cualquier posición no normativa o no binómica más allá del sexo-género-sexualidad, de forma que no hay una sola manera de pensar o de devenir lo queer.

Brad Epps ofrece una interesante reflexión sobre la significación de queer directamente aplicada a la narrativa de Gabriela Cabezón Cámara, pues si queer implica huir de esencialismos y normalizaciones, el concepto entabla una proble-

España y Latinoamérica a fines del siglo XX, Madrid-Fránkfort: Iberoamericana-Vervuert, 2018, pp. 123-140, p. 136.

${ }^{3}$ P.B. Preciado. «Multitudes queer». Nombres. Revista de filosofía, vol. xv, núm. 19 (2005), pp. 157-166, p. 162.

${ }^{4}$ J. Sáez. "Queer», en R. Lucas Platero, M. Rosón y E. Ortega (eds.), Barbarismos queer y otras esdrújulas, Barcelona: Bellaterra, 2017, pp. 381-388, p. 382. 
mática relación con categorías esencialistas como son gay, lesbiana e incluso -aunque con algunos matices ${ }^{5}$ trans:

Es precisamente en la apuesta por la volatización de todo fundamento y naturalización de toda esencia que lo queer pretende apartarse de lo gay, lésbico e incluso de lo trans, volcados, al menos en su formulación contradictoriamente mayoritaria, a la estabilización de identidades, comunidades y proyectos políticos ${ }^{6}$.

La hipótesis de la que partimos reside en que la narrativa de Gabriela Cabezón Cámara expresa precisamente esta subversión que implica lo queer a través de una creación que va más allá de los parámetros LGTB. En sus novelas se articulan una serie de discursos que reconstruyen y superponen «lenguajes, géneros y problemas»", al igual que sucede con los diferentes tipos de identidad sexual que acumulan sus personajes. Mediante su escritura, Gabriela Cabezón Cámara consigue crear productos narrativos muy innovadores especialmente dentro de una posible «apuesta queer» que no está exenta de polémica o revisión.

El propósito de esta autora parece partir de que para narrar un mundo en el que las identidades alienadas y deconstruidas de la norma heteropatriarcal puedan vivir -y no meramente sobrevivir-, debe existir un mundo igualmente deconstruido. En ese sentido es indispensable el apunte de Guadalupe Maradei: si un elemento caracteriza los finales de Gabriela Cabezón Cámara, este es precisamente su ilusión de realidad, es decir, su irrealidad. En la generación de su mundo ficcional, trata de ofrecer un reflejo de la situación argentina actual o pasada, pero un reflejo ilusorio. El final de La Virgen Cabeza o de Le viste la cara a Dios evidencia precisamente este espejismo de realidad en el acto de huida, a Madrid y a Miami respectivamente, tan idílico como imposible.

Repasaremos cómo la autora desarma la heteronormatividad en la figura protagonista de la primera de sus cuatro novelas: el personaje de Cleopatra en La Virgen Cabeza. Hemos decidido no incluir el resto de su producción -que hemos enumerado anteriormente- en el presente análisis debido al espacio que aquí nos limita, aunque en ellas también se observan muestras de este discurso queer. En el Romance de la Negra Rubia, por ejemplo, la protagonista queda desfigurada tras quemarse a lo bonzo para evitar un desahucio y es expuesta más tarde por el Gobierno bonaerense como una performance artística; este sino la lleva a conocer a una aristócrata austriaca con la que entabla una relación lésbica y poliamorosa. También en Las aventuras de la China Iron, donde la china sin nombre madre de los hijos del

5 Considero que Brad Epps resulta poco preciso o poco afortunado al usar la expresión «trans». Lo «trans» no tendría, a mi parecer, ningún tipo de relación con respecto a posiciones hegemónicas, como sí podrían llegar a ostentar identidades "transexuales» o "transgénero». Algunxs autorxs como Jack Halberstam o Lucas R. Platero despejan esta ambigüedad ańadiendo un asterisco («trans*»), como veremos más adelante.

${ }^{6}$ B. Epps. «Los fráxitos de la disidencia sexual», en D. Ingenschay (ed.), Eventos del deseo..., pp. 9-26, p. 17.

7 G. MARAdei. “Ficciones postdictadura: la trilogía oscura...», p. 138. 
Martín Fierro en el poema fundacional de José Hernández, El gaucho Martín Fierro (1872), tomará su voz como narradora para adoptar diferentes posiciones discursivas en relación con el sexo-género a lo largo de las peripecias de su viaje.

\section{IMAGINARIOS POPULARES EN LA VIRGEN CABEZA: CLEOPATRA Y EL NEOBARROSO}

En La Virgen Cabeza, una travesti villera de la periferia bonaerense, Cleopatra, genera un culto religioso en torno a su figura tras una revelación mariana. Gracias a ello, consigue organizar la villa miseria de El Poso para mejorar la calidad de vida de sus habitantes. Qüity, una cronista de la ciudad, se interesa por el caso y se traslada a la villa para cubrir un reportaje. Finalmente acaba enamorándose de Cleopatra y formando una familia con ella tras la destrucción total de El Poso por parte de los poderes inmobiliarios, que pretenden especular con los terrenos. La novela está dividida en veinticinco capítulos y un epílogo, y presenta dos narradoras: por un lado, la voz de Qüity narra veinte de ellos en un tono a medio camino entre la crónica periodística, la novela criminal y el género testimonial; y por otro, la misma Cleopatra (Cleo), en apenas cinco capítulos intercalados, presenta su propia visión de la historia a modo de contrapunto. Cleo nos ofrece su versión de la misma forma en la que aparecen sus intervenciones en el conjunto de la obra, usando el lenguaje de los pibes chorros de las villas miseria.

De esta forma, durante la novela asistimos a un juego narrativo que permite conocer la identidad del personaje de Cleopatra a través de dos discursos: el suyo propio, y mayormente el de Qüity. Esta voz doble tendrá una justificación diegética, pues se plantea una historia marco: tras las traumáticas vivencias experimentadas en la villa miseria, Qüity se ha propuesto plasmar estos sucesos desde el exilio en una novela -que es, dentro de la ficción, la que estamos leyendo-. No obstante, Cleo decide intervenir para exponer su punto de vista de los acontecimientos a través de cintas orales que después Qüity transcribe e incluye en el texto. En sus intervenciones, Cleo se va a rebelar contra la autoridad discursiva que supone Qüity, reivindicándose como sujeto experiencial, autorizando sus creencias y su visión frente al descrédito de esta, y creando un diálogo entre ambas voces narrativas.

La primera descripción de Cleopatra en la novela proviene de la voz de Qüity, que la describe en el presente de la enunciación -es decir, desde el exilio y tras la destrucción de la villa-: «Bella y parlante como es [...] Toda hogar [...] ella es pura alegría blanca y radiante y maricona y devota y enamorada y está siempre como entre boleros de novia camino al altar ${ }^{8}$. La definición condensa muy acertadamente los rasgos fundamentales de Cleo mediante diferentes adjetivos como «alegre», «radiante», «maricona» $\mathrm{y}$ «devota». Más tarde, en su primera inclusión narra-

${ }^{8}$ G. Cabezón Cámara. La Virgen Cabeza, Buenos Aires: Eterna Cadencia, 2009, p. 15. 
tiva, Cleopatra va a aventurarse en su autodefinición, afirmándose como «médium» de la Virgen y como «no macho»:

No, no sé por qué, tal vez la cansemos sus médiums, somos todas unas minas, seremos chusmas. Que los chongos también son chusmas. Sí, ya lo sé. Bueno, seré machista yo también, Qüity, aunque haya renunciado a ser un macho según decís vos [...] La verdad es que nunca fui un macho, querida mía (22).

Cleopatra confirma dos de los rasgos - «maricona» y «devota»- que ha proporcionado la descripción de Qüity, pero matizándolos - «aunque haya renunciado a ser un macho según decís vos». Además, añade un elemento decisivo: es «chusma», es villera ${ }^{9}$, se sitúa en la periferia social, cultural y territorial de la urbe. En esta línea, durante el momento previo a su primer encuentro, Qüity se aventura a definir a Cleopatra como «una travesti que organiza una villa gracias a su comunicación con la madre celestial, una niña Lourdes chupapijas, una santa puta y con verga» (31). Estas definiciones resultan de gran interés porque destacan el conjunto de narrativas que se cruzan en el discurso identitario del personaje, que acumula religión («médium», "devota», "santa», "niña Lourdes»), sexualidad ("travesti», "maricona», "chupapijas», "no macho», "puta» "con verga», "chongo») y estrato social («chusma», "villa»).

La estética de acumulación de narrativas y discursos que presenta la novela ha sido identificada como neobarroso ${ }^{10}$ por varios críticos (Tozzil, Maradei) que toman prestada la terminología de Néstor Perlongher en «Caribe transplatino» (2008), para aquella escritura que hace de la heterogeneidad su punto de anclaje composicional y lingüístico: un barroco combativo que permite en su acumulación la desarticulación del significado. Gabriela Cabezón Cámara escoge diferentes narrativas y discursos populares y los tritura, los deforma y aúna para crear, en este preciso acto de reapropiación, su arma beligerante. En La Virgen Cabeza, Cleopatra hablará como una villera y cantará reaggeton, pero con la letra de un cancionero antiguo; citará referentes de la alta cultura desde la Odisea (17), Alfonso X (88) o Petrarca (101) hasta la poesía gauchesca -en la cumbia elegiaca a Torito (100)-. Las descripciones de Cleopatra evidencian esta heterogeneidad de discursos que son reconocibles como neobarroso.

Dentro de esta propuesta estética, el uso de elementos de la cultura popular ostenta un papel fundamental para construir nuevos discursos híbridos. En la obra de Gabriela Cabezón Cámara este proceso se concretiza en la identidad de Cleopatra, ya que se muestra todo un entramado de referencias heterogéneas que configuran un universo kitsch sobre el que se construye el personaje. La primera de estas

9 Las villas miseria argentinas, al igual que las favelas brasileñas o las chabolas españolas, son espacios de crecimiento desordenado, sin planificación urbanística, y definidos por la marginalidad económica y social, en este caso respecto a Buenos Aires.

${ }_{10}$ Podemos identificar algunos de los rasgos del neobarroso con otras fórmulas estéticas apuntadas por la crítica, como Carolina Ruiz, que utiliza «lo pobre lindo», o Alberto Ponze, que habla de «neocultura». En cualquier caso, la mayor acogida crítica la ostenta el concepto de neobarroso. 
referencias es la imitación de una de las presentadoras de televisión argentinas más conocidas, Susana Giménez, por parte de la Cleopatra adolescente:

Tenía doce años, todavía se llamaba Carlos Guillermo y su padre casi la había matado a trompadas «por puto del orto» según le explicó al periodista de Crónica que tituló: «Barbarie homofóbica. Casi mata a su hijo mayor porque el nene quiere ser como Susana». Fueron a entrevistarla al hospital, la diva se conmovió cuando supo cuánto le adoraba el nene, lo invitó a su programa y ahí Carlos Guillermo decididamente se transformó en Kleo, todavía en muletas, pero bailando encantada con boas que la diva le puso en el cuello (34).

Esta imitación y reproducción de los roles de género es enfatizada por algunas de las principales pensadoras de la teoría queer como Teresa de Lauretis en «Las tecnologías del género" (1989) o Judith Buter en El género en disputa (1990) por ser clave para exponer la estructura binaria del género. De esta manera, la imitación de la feminidad -en este caso, identificada en el referente concreto de Susana Giménez- por parte de un sujeto al que se le ha asignado el género masculino -el propio Carlos Guillermo- desnaturaliza la normatividad del binomio hombre/mujer. Se crea así un espacio de disidencia donde pretende situarse la noción de queer que trabajaremos de forma más desarrollada en el siguiente apartado, y además se destaca la violencia estructural y física que se desata sobre el sujeto disidente ${ }^{11}$.

Por otro lado, Cleo también interpreta, en diferentes momentos, una performance del personaje histórico de Eva Perón: «Adoptó, después de que Dios le habló, un look Eva Perón» (33); «si Evita viviera ¿̇levaría a Cleo a trabajar con ella codo con codo a la Fundación?» (87). Mediante la apropiación de esta figura del imaginario cultural argentino, Cleopatra va a usar su contacto divino para ayudar a El Poso, va a ser el motor de cambio de la miseria en que está sumida la villa resignificándose como un mito para sus habitantes. La Eva Perón que ayudaba a los pobres, la Eva Perón santa, se posiciona ahora en la periferia del discurso peronista como una Eva Perón travestida ${ }^{12}$. Como en el caso de Susana Giménez, una figura que

${ }^{11}$ En este punto resulta imprescindible la referencia a las novelas de Manuel Puig en la tradición literaria argentina. En ellas, los personajes principales reproducen sus vivencias y su aprendizaje en torno a las grandes divas de las superproducciones de Hollywood de los años 40 y 50 . Realizan así un cortocircuito en la posición del binomio de género que les ha sido asignado: hombres que viven como mujeres - no exactamente trans-, que se performativizan como tal y que se enfrentan de esta forma a la estructura heteropatriarcal a partir de uno de sus medios de reproducción más potentes, la tecnología del género que supone el cine. En este punto el personaje de Cleopatra podría guardar cierta similitud con el Molina de El beso de la mujer araña (1976) o el joven Toto en La traición de Rita Hayworth (1968), pero desviando el objeto de imitación de las grandes divas de Hollywood hacia las tertulianas y presentadoras de la televisión de masas argentina; y cambiando el contexto social de la clase media provinciana a los habitantes de las villas miseria.

${ }^{12}$ El dramaturgo Copi ya trabajó este motivo en una de sus obras de teatro, Eva Perón (1969), donde un actor travestido interpreta a Evita y finge su muerte para poder liberarse del cúmulo de significaciones en las que había desembocado su figura. Para ello, mata a su enfermera, fiel peronista, y usa el cadáver para simular el suyo propio. Tal y como indica Patricio Pron, el papel de Eva 
el imaginario cultural cultiva como idealmente femenina queda apropiada por un personaje que se siente en la periferia del binomio de género.

En la misma línea, Cleopatra realiza un ejercicio de usurpación del discurso religioso. En su conexión con la madre celestial, este personaje toma a la Virgen María como una diva más en su repertorio, como Susana Giménez o Evita: «No, la Virgen no dice nada. A ella que es una estrella hace dos mil años te imaginarás que la fama perecedera no le interesa» (14). En la escena del milagro, como si de un pasaje bíblico se tratara, se narra cómo tras ser violada y apaleada por los policías, Cleo es "resucitada» por la Virgen. Los policías quedan atónitos y la noticia se expande por la villa: «Le pegaron y se la cogieron entre todos, incluidos los presos [...] la Virgen [...] me sentó en sus rodillas y me dijo que no me preocupe, que ella me iba a cuidar» (35).

A partir de esta escena, los habitantes de la villa comienzan a profesar culto a la llamada Virgen Cabeza -realizada sobre un bloque de cemento y con una cabeza de grandes dimensiones- y van a seguir las órdenes de Cleo para mejorar sus condiciones de vida: crean un estanque de carpas para tener qué comer o instalan cámaras de seguridad para reducir la delincuencia. En el capítulo viI se relata una procesión de las figuras de la Virgen Cabeza y de otros santos exacerbados hasta la parodia -Qüity los tilda de "extraterrestres» (55) - que sin embargo han generado la esperanza en el pueblo. La voz narradora de Qüity realiza una interesante relación entre esta deformidad y el vínculo comunitario:

La desproporción era necesaria para expresar la esperanza de los pobres, tan ofendidos, tan golpeados y tan humillados y sin embargo tan dispuestos a creer en que hay una salvación para ellos: el escultor, las travestis, las pibas, las gordas desdentadas, los pibes chorros, los albañiles, estaban todos reunidos ahí en El Poso convencidos de que la Virgen iba a protegerlos (57).

Este acercamiento de las figuras religiosas a los habitantes de la villa queda reflejado también lingüísticamente. Cleopatra hace hablar a la Virgen de Luján en el lenguaje de los villeros y los pibes chorros, afirmando, por ejemplo, que la Virgen es una "forra violada por una paloma» (129); que le ha propuesto un matrimonio con su hijo: "Que me case con su hijo» (35); o le narrará sus dolores en el parto: "Algo así como cagar una sandía dice que fue» $(66)^{13}$. Todo ello configura un universo religioso cuya lectura resulta un acto de parodia con respecto al discurso ofi-

Perón como una imagen para el régimen peronista posibilita su juego en la lectura trans: una imagen (travesti) se encuentra representando -realizando la performance- de otra imagen (Eva Perón), reflexionando así sobre la identidad y el compromiso de la figura histórica.

13 En este sentido recomiendo la lectura de Guadalupe Maradei, que realiza una genealogía del adjetivo "Cabeza» y su implicación en esta «villerización» de la Virgen. Esta investigadora explica cómo hace referencia al nombre «cabeza negra», que se usaba de forma despectiva para designar a los migrantes de ascendencia indígena que llegaban a la capital argentina en el periodo de industrialización peronista de los años 40. Pervive en la actualidad en las clases medias y altas para designar a sujetos de clase trabajadora y tez oscura. Junto a este significado ha surgido un segundo uso para referirse a 
cial caracterizado por la rigidez, que Cleo subvierte escatológicamente -o más bien neobarrosamente-, como si la Virgen fuera una villera más cantando una cumbia.

A propósito del lenguaje y del género musical de la cumbia villera, De Gori explica cómo la cumbia es un lenguaje en los límites, enunciado desde sujetos desposeídos que revitalizan y reivindican una cultura propia. Este género musical produce un efecto de desagrado, incluso de parodia, para todo aquel que no esté familiarizado con su código. Determinados capítulos de la obra comienzan con fragmentos de cumbia que acompañan al uso del lenguaje que se da en ella: «Todo empezó con los canas / que me rompieron la cara / ahí vino Santa María / que me la dejó bien sana / y dijo que no quería / que yo ande chupando pijas / como crazy todo el día» (33). Al utilizar este código, Cleopatra y el resto de villeros introducen al lector en el mundo de estos desposeídos urbanos que se afirman "positivamente constituyendo una identidad y un movimiento cultural opuesto a la riqueza y a la ausencia de posesión de bienes materiales y culturales» (De Gori 366).

\section{CLEOPATRA COMO SUJETO QUEER}

Estas fugas de contenido y resignificaciones múltiples que difunden las barreras entre estratos sociales, lenguajes y culturas, y que representan la estética neobarrosa en la novela, también van a darse con respecto a las categorías sexuales tradicionales. De esta forma, escapando del esencialismo de los movimientos identitarios LGTB, La Virgen Cabeza propone una «apuesta de discurso queer» como comentábamos al inicio del presente trabajo. El personaje de Cleopatra va a posicionarse en varios puntos de la obra encarnando diferentes identidades LGTB, no con un orden temporal que podría sugerir una evolución o un "progreso» en su identidad, sino de una forma aleatoria que provoca más bien un efecto de indefinición o mestizaje.

En el inicio de la historia de Cleopatra, se dice que es puto: «Su padre casi lo había matado a trompicones por "puto del orto"» (Cabezón Cámara, Virgen 34). Se remite así a su infancia/juventud, en la que con el nombre de Carlos Guillermo realizaba conductas asociadas a la homosexualidad y tenía vivencias relacionadas con esta: imitar a Susana Giménez, ser apalizado por su padre como respuesta a su feminidad o ser violado por el guía espiritual de la villa, el padre Julio. Esta identidad es definida no por su propia voz, sino por otros personajes, de forma que incluso cuando parece haberla abandonado los canas de la villa continúan concibiéndola así: "Al grito de "marica de mierda ahora vas a ver lo que es un macho" la pegaron y se la cogieron entre todos» (35). Uno de los aspectos más curiosos respecto a esta identidad como "puto»/«marica» reside en que, junto a los discursos de odio que se le imponen, como en el caso de su hermano - «Antes decía boludeces tipo "en esta familia seremos faloperos pero putos no"» (61) o «tiene que ser el puto del orto de

una persona mal vestida, desagradable, que no responde a los cánones de la cultura dominante. Para Maradei este nuevo uso no hace sino actualizar los efectos de discurso sobre la raza del uso anterior. 
mi hermano Carlos Guillermo» (61)-, encontramos también en personajes como Qüity estos vocablos para referirse a ella. Resulta interesante recordar que para lo que Cleopatra define como "no macho», su compañera sentimental usa la expresión «maricona» (15), al igual que los ya citados discursos de odio - pero con la diferencia, bastante significativa, de cambiar su género gramatical al femenino-.

Tras el relato de la paliza que su padre le propina, se dice que es invitado al show de Susana Giménez y allí «Carlos Guillermo decididamente se transformó en Kleo" (34). En un primer momento, podemos pensar que a partir de este suceso pasa a representar una identidad transgénero en la que se identifica como mujer. Esta idea se repite a lo largo de la narración tanto desde la voz autorial de Qüity: «Mi mujer es la elegida de la Virgen» (115) como por la de la misma Cleo: «Y ya ves, te conseguistes la mejor historia, la mejor mina» (78); «nunca hacían esos "trabajos de chongo que le arruinan el cuerpo a cualquier chica" como me explicó Cleo» (55) o "Yo me los imaginaba, a veces cuando ya era una chica, ligándose un peluche por cada negro muerto" (91).

De esta manera, su posible posición como sujeto mujer va tomando fuerza para el lector a lo largo de la obra. Ejemplo de ello resulta la anécdota donde menciona su intervención quirúrgica para tener implantes mamarios: "Además, me enseñó las cosas de Dios y a leer bien y me mandó a la escuela nocturna y me pagó estas tetas a los diecisiete» (37). De esta conversión a Cleopatra Qüity afirma que, a modo de meta, alcanza la plasmación legislativa en su identificación: «Cleo logró uno de sus sueños más difíciles: tener su nombre en los documentos. Desde entonces, por fin y para siempre se llama Cleopatra Lobos» (19). No obstante, este hecho, que se reconoce como reivindicación colectiva de las mujeres transgénero, queda rechazado por la misma Cleo más adelante, contradiciendo la aseveración anterior de Qüity: «Y no estamos hablando de que nos pongan nuestros nombres de mujer en los documentos, total nadie tenía documentos allá, estábamos hablando del derecho a vivir aunque nos dijeran Guillermo, Jonathan o Ramón» (93).

Quizás esta contradicción conduce a repensar la identidad supuestamente transgénero de la protagonista, pues al fin y al cabo nunca se explicita como «transgénero» en la narración, sino que esta interpretación se reduce a un efecto de sentido que provoca en el lector, desprendido de sus propias categorías previas en cuanto a identidades LGTB se refiere. De esta manera, la categoría mujer pronto se problematiza al encontrar episodios en los que Cleopatra resalta orgullosa que mantiene «la poronga más grande del conurbano bonaerense...» (78) o en los que se define a sí misma como travesti «como si no supieras que antes de la Virgen yo era puta ¿De qué mierdas te creés que vivimos las travestis, mi amor?» (75). Precisamente este término, «travesti $»^{14}$, es el que emplean ambas voces narrativas para hacer referencia en

${ }^{14}$ La inclinación hacia el término «travesti» puede tener explicación en el contexto argentino dentro de los movimientos activistas de personas trans, que han usado y usan con frecuencia esta denominación de forma reivindicativa, como se muestra en M.S. Cutuli y S.J. Insausti. "Cabarets, corsos y teatros de revista: espacios de transgresión y celebración en la memoria marica», 
varias ocasiones tanto a la identidad de Cleopatra como a la del resto de sus compañeras de la villa: «La "travesti santa", rodeada por una corte de chongos, putas, nenes y otras travestis, predicaba abrazada a la estatua de la Virgen que un albañil agradecido le había hecho en el potrero de la villa» (34); «Las "hermanitas", ex compañeras de trabajo de Cleopatra, iban y venían presurosas llevando basura, trayendo caballetes y tablones, todo en la espalda como buenas, industriosas y maquilladísimas hormiguitas travestis» (52) o «Y no te creas que por travesti le vas a poder bajar la caña: mi tía, tan señorita como la ves, te va a dar con un tronco. Antes de ser famosa por la Virgen, ya era famosa por la anaconda que tiene» (118).

Por otro lado, a pesar de que Qüity en su narración identifica a Cleopatra como «travesti» de forma genérica, marca un matiz entre la Cleopatra transgénero/ travesti y la Kleo prostituta que se anuncia en páginas de prostitución: «Cleopatra, Kleo cuando anunciaba en el rubro 59» (33). Aunque esta contracción de su nombre con variante ortográfica incluida pueda sencillamente atribuirse a un nombre artístico - una disociación muy común, por otra parte, en el universo travesti y no tanto en el transgénero-, no deja de plantear una disyuntiva más en su identidad: el significante "Cleopatra" es asociado a su vida diaria como mujer transgénero/travesti, y el significante «Kleo» a su actividad laboral como prostituta travesti. Se disparan aún más, si cabe, las posibles lecturas sobre su identidad y su posible pertenencia a determinadas categorías que oscilan entre Carlos Guillermo como puto, Cleopatra como transgénero/travesti y Kleo como nombre artístico travesti.

La identidad en este punto puede ser mejor entendida con el término "trans», que permite oscilar al personaje entre diferentes categorías (transgénero, transexual, travesti) que tienen en común la oposición al concepto de cisgénero -o conforme con el género asignado-. En referencia al término «trans», algunos teóricos como Jack Halberstam proponen su uso con asterisco, asociando el término "trans» a identidades fijas y estables, y proponiendo así incidir aún más en las posibilidades de la variabilidad de género mediante un «trans*» más abierto y divergente:

He seleccionado el término «trans*» para este libro, precisamente para abrir el término a un despliegue de categorías de organización que no se limiten a la variación de género. Como veremos, el asterisco modifica el significado de transitividad al negarse a situar la transición en relación con un destino, con una forma específica o con una configuración establecida de deseo e identidad [...] convierte a las personas trans* en autoras de su propia categorización ${ }^{15}$.

En relación con este "trans*», la identidad que presenta el personaje de Cleopatra responde muy bien a su nuevo significado, ya que se aleja de la idea de transición hacia un destino. El desorden discursivo con el que la novela presenta los dife-

en R.M. Mérida Jiménez y J.L. Peralta (eds.), Memorias, identidades y experiencias trans (in)visibilidades entre Argentina y España, Buenos Aires: Biblios, 2016, pp. 12-31.

15 J. Halberstam. Trans*. Una guía rápida y peculiar de la variabilidad de género. Madrid-Barcelona: Egales, 2018, pp. 36-37. 
rentes términos con los que Cleopatra evidencia una historia de vida no se sitúan en el tradicional camino niño $>$ marica $>$ transición $>$ mujer trans $>$ mujer completa, sino que desde el principio se habla de Cleopatra como «mujer», "puto» o "travesti» de forma intermitente, desordenada y por parte de diferentes voces discursivas. Además, en ningún momento el personaje plantea realizarse una cirugía de las denominadas "cambio de sexo» o "reasignación», sino que incluso utiliza sus órganos genitales masculinos de forma satisfactoria: «Me acomodó con las piernas abiertas sobre su falda y se la levantó apenas y me entró en la concha con ese porongón que tiene y que me pareció a medida para mí» (141).

Al final de la novela, después de la tragedia de la villa y de tener las relaciones sexuales con Qütity que muestra el anterior fragmento, Cleo adoptará una nueva identidad LGTB respecto a su orientación sexual, se identificará como «lesbiana» (no como heterosexual o bisexual): «Ves mi amor, que Dios existe. Es como si ayer hubiera muerto un poco cuando me enterraron y hubiera resucitado distinta. Lesbiana resucité, me parece» (141). ¿Deja Cleopatra de ser el "puto» al que su padre apalizaba por asumirse lesbiana? ¿Puede Kleo ser travesti y al mismo tiempo conseguir la plasmación legal de su identidad «mujer» en su pasaporte? Ante tal amalgama de identidades que presenta el personaje, no se puede sino asumir que Cleopatra no representa de forma esencial ninguna de ellas, y que las deviene en diferentes momentos o incluso al mismo tiempo ${ }^{16}$.

No en vano, al comienzo de la novela la voz narrativa de Qüity afirma, casi a modo de reflexión teórica, que de las dos Cleopatra es «la más queer» (17). El hecho de que el calificativo provenga del personaje que representa su gran contrapunto en la narración y su actual pareja sentimental en el presente de la enunciación nos invita a pensar en Cleopatra como sujeto queer de la forma más explícita posible. Gabriela Cabezón Cámara asume en este punto la no identidad de la que hablábamos al inicio de este trabajo y la expone de una forma integral: en el acto de lectura eliminamos así toda posibilidad de concebir a Cleopatra de una forma esencial, presocial o innata. Qüity expone la inefabilidad identitaria de su compañera en un acto metareflexivo, y por ello decide queer para definir -o indefinir-, con una sola palabra, sus continuos devenires: el puto, la lesbiana, el hombre, la mujer, la trans (la travesti, la transgénero).

Paul B. Preciado en sus «Multitudes queer» enumera precisamente como una política queer la «desontologización de la práctica sexual». Los tipos de sujetos anor-

16 El desorden narrativo en relación con las identidades de Cleopatra puede ser entendido como una concepción queer de las relaciones temporales (Queer time) del modo en que lo trabaja Jack Halberstam: «I suggest new ways of understanding the nonnormative logics and organization of community, sexual identity, embodiment, and activity in space and time. "Queer time" is a term for those specific models of temporality that emerge within postmodernism once one leaves the temporal frames of bourgeois reproduction and family, longevity, risk/safety, and inheritance» (J. Halberstam. In a Queer Time and Place. Transgender Bodies Subcultural Lives. Nueva York-Londres: New York University Press, p. 6). 
males que enuncia este autor en su ensayo incluirían a las «trans-maricas sin polla» ${ }^{17}$. Sin duda podríamos aquí entender también como sujeto central -o más bien, permanentemente periférico- de las multitudes queer a la "transbollera sin coño» que, usando el lenguaje de Preciado, es Cleopatra -aunque no olvidemos que para Qüity es, al mismo tiempo, «maricona». Al coincidir en términos tan contradictorios como ser al mismo tiempo "maricona» y «lesbiana» -al menos, en el sentido estricto-, el personaje redunda en otra de las políticas que enumera Preciado: la «desidentificación», precisamente a partir de la hiperidentificación.

Este sabotaje de las identidades esencialistas LGTB no es sino una más entre las múltiples reinterpretaciones de discursos, hegemonías e imaginarios que deshace la novela. Como si de una trituradora se tratara, Gabriela Cabezón Cámara destruye y reconstruye a su antojo para reapropiarse de ellos después, en un acto de empoderamiento narrativo. Justamente a esto mismo se refiere Guadalupe Maradei cuando, en su análisis sobre el uso de la religión en la obra, afirma que resulta

una provocación, entonces, porque una corporalidad travesti generizada, racializada, subalternizada es erigida como interlocutora y médium de una figura sacra [...] Obra en este sentido un trabajo con la lengua que se constituye como marca distintiva de la escritura de Cabezón Cámara: la exhibición del poder del mito a través de la usurpación de su lenguaje ${ }^{18}$.

Según indica Maradei, la provocación no solo opera en el plano de las identidades sexuales y de género, sino también de la exclusión económica, social o racial. En este sentido resulta evidente la insistencia de la crítica en remarcar el resto de aspectos que definen a Cleopatra como sujeto excluido (Maristany, Ponze). Esta es precisamente la "propuesta queer» que presenta el texto, aquella que mediante el neobarroso tritura discursos y los engulle para hacerlos suyos, enorgulleciendo los populares, vejados o subalternos, y bajando los oficiales y hegemónicos a su mismo nivel. A colación viene la definición de queer de Javier Sáez que hemos citado y que reivindicaba precisamente esta solidaridad de alteridades. Una disidencia sexual que se recrea en la acumulación como arma de desarticulación del patriarcado, y sobre todo - como indica Maradei- de supervivencia.

\section{CONCLUSIONES. HACIA UNA UTOPÍA QUEER}

A modo de conclusión, resulta interesante atender a las palabras de Gabriela Cabezón Cámara en una entrevista -tras la aparición de La Virgen Cabeza en 2009donde la periodista Paula Jiménez pregunta a nuestra autora: «La mezcla de culturas en tu novela, ¿puede pensarse también como una apuesta queern? Gabriela Cabezón Cámara responde:

17 P.B. Preciado. «Multitudes queer», p. I63.

${ }^{18}$ G. Maradei. "Ficciones postdictadura: la trilogía oscura...", p. 135. 
Sí. La diferencia entre la alta y la baja cultura está disuelta. Esto puede considerarse como una apuesta de lo que una quisiera que sucediera con las identidades en la sociedad. Que se mezcle la travesti con el presidente de la nación, no en una relación prostibularia sino en una igualitaria, en un ámbito público, por ejemplo. Que cada uno se mezcle con lo que le dé las ganas de mezclarse ${ }^{19}$.

Ante la imposibilidad de que esta mezcla se produzca en la realidad, al menos por el momento, Gabriela Cabezón Cámara propone ficciones donde la hace posible. Tanto en la novela que acabamos de analizar como en el resto de su obra, se evidencia esta voluntad de empoderamiento que nos hace soñar en última instancia, y como sugiere Maristany, en una utopía tanto en el terreno corporal y sexual como en el orden de lo económico. Una utopía para ser queer. Una utopía tal y como se muestra en el final de su última novela, Las aventuras de la China Iron, en la que los protagonistas y los indios mapuches crean su propia patria sin géneros ni sexualidades preestablecidas en el delta del Paraná. Es el utópico nacimiento de otra Argentina posible, la nación postcolonial y travesti de la que Qüity y Cleo son, contradictoriamente según la cronología ficcional, sus fundadoras.

Recibido: abril de 2019. Aceptado: mayo de 2019

19 G. Cabezón Cámara. «Cabecita loca». Página 12, 15 de julio de 2009. http://www. pagina12.com.ar/diario/suplementos/soy/1-861-2009-07-15.html. Consultado el 14 de febrero de 2019. 


\section{BIBLIOGRAFÍA}

Butler, Judith. El género en disputa. Barcelona: Paidós, 2007.

Cabezón Cámara, Gabriela. La Virgen Cabeza. Buenos Aires: Eterna Cadencia, 2009.

Cabezón Cámara, Gabriela. "Cabecita loca». Página 12, 15 de julio de 2009, Web consultada el 14 de febrero de 2019, http://www.pagina12.com.ar/diario/suplementos/soy/1-861-200907-15.html.

Cabezón Cámara, Gabriela. Le viste la cara a Dios. Buenos Aires: La isla de la luna, 2011.

Cabezón Cámara, Gabriela. Romance de la Negra Rubia. Buenos Aires: Eterna Cadencia, 2014.

Cabezón Cámara, Gabriela. Las aventuras de la China Iron. Buenos Aires: Random House, 2017.

Cabezón Cámara, Gabriela e Iñaki Echeverría. Beya. Le viste la cara a Dios. Buenos Aires: Eterna Cadencia, 2013.

Cabezón CÁmara, Gabriela e Iñaki Echeverría. Y su despojo fue una muchedumbre. Buenos Aires: Cazador de ratas, 2015.

Córdoba, David. «Teoría queer: Reflexiones sobre sexo, sexualidad e identidad. Hacia una politización de la sexualidad», en David Córdoba, Javier Sáez y Francisco Vidarte (eds.), Teoría queer. Politicas bollera, maricas, trans, mestizas, Barcelona-Madrid: Egales, 2005, pp. 21-66.

Cutuli, María Soledad y Santiago Joaquín InSAusti. "Cabarets, corsos y teatros de revista: espacios de transgresión y celebración en la memoria marica», en Rafael M. MÉRIDA JIMÉNEZ y Jorge Luis Peralta (eds.), Memorias, identidades y experiencias trans (in)visibilidades entre Argentina y España, Buenos Aires: Biblios, 2016, pp. 12-31.

De Gori, Esteban. «Notas sociológicas sobre la cumbia villera. Lectura del Drama Social Urbano». Convergencia. Revista de Ciencias Sociales, vol. 12 (2005), pp. 353-372.

De Lauretis, Teresa. «La tecnología del género», Web consultada el 16 de febrero de 2019, http:// blogs.fad.unam.mx/asignatura/adriana_raggi/wp-content/uploads/2013/12/teconologias-del-genero-teresa-de-lauretis.pdf.

Drucaroff, Elsa. Los prisioneros de la torre. Politica, relatos y jóvenes en la Postdictadura. Buenos Aires: Emecé, 2011.

Epps, Brad. «Los fráxitos de la disidencia sexual», en Dieter Ingenschay (ed.), Eventos del deseo: sexualidades minoritarias en las culturas-literaturas de España y Latinoamérica a fines del siglo XX, Madrid-Fránkfort: Iberoamericana-Vervuert, 2018, pp. 9-26.

Gallego, Ana. «Comienzos de la novísima novela argentina (2001-2011)». Hispanoamérica. Revista de literatura 130 (2015), pp. 3-14.

Halberstam, J. Jack. In a QueerTime and Place. Transgender Bodies Subcultural Lives. Nueva York-Londres: New York University Press, 2005.

Halberstam, J. Jack. Trans*. Una guía rápida y peculiar de la variabilidad de género. Madrid-Barcelona: Egales, 2018.

Hernández, José. Martín Fierro. Madrid: Cátedra, 2015.

Maradei, Guadalupe. "Ficciones postdictadura: la trilogía oscura de Gabriela Cabezón Cámara», en Dieter Ingenschay (ed.), Eventos del deseo: sexualidades minoritarias en las culturas-literaturas de España y Latinoamérica a fines del siglo XX, Madrid-Frankfurt: Iberoamericana-Vervuert, 2018, pp. 123-140. 
Maristany, Javier. «Usos de la voz subalterna. Lesbianas y travestis en dos novelas argentinas». Chasqui: revista de literatura latinoamericana, vol. 45 (2016), pp. 116-129.

Platero, R. Lucas. «Trans* (con asterisco)», en R. Lucas Platero, María Rosón y Esther Ortega (eds.), Barbarismos queer y otras esdrújulas, Barcelona: Bellaterra, 2017, pp. 409-415.

Perlongher, Néstor. Prosa Plebeya. Ensayos 1980-1992. Selección y prólogo de Christian Ferrer y Osvaldo Baigorria. Buenos Aires: CoLihue, 2008.

Ponze, Alberto. «La virgen Cabeza: las voces de la villa y de las diversidades sexuales». Antares: Letras e Humanidades, vol. 9, núm. 17 (2017), pp. 32-49.

Puig, Manuel. La traición de Rita Hayworth. Barcelona: Seix Barral, 1971.

Puig, Manuel. El beso de la mujer araña. Barcelona: Seix Barral, 1976.

Preciado, Paul B. "Multitudes queer». Nombres. Revista de filosofía, vol. xv, núm. 19 (2005), pp. 157-166.

Pron, Patricio. «Un argumento sobre su excepción: acerca del travestismo de Eva Perón en la pieza teatral de Copi». Anales de literatura hispanoamericana, vol. 36 (2007), pp. 269-281.

Ruız, Carolina. "Cuerpos y literatura disidente. La Virgen Cabeza, de Gabriela Cabezón Cámara». Badebec, vol. 6, núm. 12 (2017), pp. 352-365.

Sáez, Javier. "Queer», en R. Lucas Platero, María Rosón y Esther Ortega (eds.), Barbarismos queer y otras esdrújulas, Barcelona: Bellaterra, 2017, pp. 381-388.

TozzI, Liliana. «Representaciones del espacio urbano y configuraciones identitarias en la literatura argentina del siglo xxI». Vistas al patio, vol. 17 (2017), pp. 69-87. 